\title{
Application of Maximum Power Point Tracking Algorithm for Determination of the Solar Electric Potential in Gorkha Bazzar, Nepal
}

\author{
Aamod Khatiwada ${ }^{1}$, Rabin Dhakal ${ }^{2}$, Sirapa Shrestha ${ }^{2}$ \\ ${ }^{1}$ Department of Electronics and Communication Engineering, Thapathali Campus, Institute \\ of Engineering, Tribhuvan University, Kathmandu, Nepal \\ ${ }^{2}$ Department of Mechanical Engineering School of Engineering, Kathmandu University, \\ Kavre, Nepal \\ 1'aamod@tcioe.edu.np, ${ }^{2}$ rabin.dhakal@ku.edu.np
}

\begin{abstract}
It is inevitable fact that the use of excessive fossil fuel has established itself as a major concern for the existence of living kinds in the world. So the development of renewable energy source has been the must task to minimize the energy crisis as well as the problems created by the use of fossil fuels. Nepal is a country with geographical and climatic diversity in South East Asia with mean solar radiation of $4.7 \mathrm{kWh} / \mathrm{m} 2$ per day and a surface area of $1,47,181 \mathrm{~km} 2$. It is the region in South East Asia with a tremendous amount of solar energy potential. Among three major geographical regions namely Himalayan, Hilly and Terai region, this study has been performed at Gorkha Municipality, located at central Nepal in Hilly region to determine the solar energy potential for grid-connected photovoltaic systems installed on rooftops. A methodology was developed, in which the characteristics of the buildings were categorized, followed by the calculation of the roof surface area where photovoltaic panels could be installed. After that, the mean solar irradiation characteristics were defined as well as the technical parameters of the photovoltaic systems. With all these factors, the amount of electricity that could be potentially generated per year by solar panels is estimated. Finally, the calculations were made to estimate the amount of electricity that could be generated with the implementation of incremental conductance method for tracking the maximum Power Point and also, the system was developed using Arduino, PHP programming language, current and voltage sensors which aids for the maintenance of the installed photovoltaic cells.
\end{abstract}

Keywords: Renewable Energy, Photovoltaic Cell, Solar Irradiation, Maximum Power Point

\section{Introduction}

The economic growth and improvement in people's living standards depends on the utilization of electrical energy. There is growing demand for electrical energy, whilst reducing carbon emissions, is one of the main reasons pushing the advancement and implementation of renewable resources such as solar photovoltaics, wind and hydropower [1] [2]. Implementing these in rural areas allow communities to generate and manage their own resources locally. With the increase in the cost of electricity 
generated using fossil fuels and improvement in technology, Solar energy is becoming a more economically attractive source of energy. By 2020, it is estimated that global solar-generating capacity will be boosted by 20 to 40 times its current level with hundreds of billions of dollars of investment in this field [3]. In fact, the conversion of solar energy into electrical energy by solar photovoltaic (PV) technology unlocks great potential and represents a technically viable and sustainable solution to rising energy demands. Solar power has many advantages in the generation of electrical energy. It has null raw fuel costs, unlimited power supply potential, and is environment-friendly. Another advantage of solar power is that it is available everywhere, even on the moon and the mars. The energy produced directly from PV cells increased from 26 Megawatts (MW) in 2000 to an estimated 21,000 MW in 2011 [4].

The rooftop Solar Energy Potential of Lahore City, Pakistan was estimated using GIS technique. The high-resolution Imagery was used to digitize the rooftops [5]. The rooftop solar potential map of Caceres, Spain was estimated by the implementation of Light Detection and Ranging (LIDAR) data of high density [6]. The total rooftop surface area of Bhopal City, India was estimated using object-oriented classification available through eCognition Developer and then MNRE standard was employed for estimating the available surface area. The obtained available surface area was used for further estimation of the PV potential of the entire residential area of the city [7]. The technical potential of photovoltaic (PV) system deployed on rooftops in the continental United States was quantified using a methodology comprising of LIDAR data, GIS methods and PV-generation modeling [8]. The rooftop potential of Greater Mumbai was estimated using a methodology comprising of sampling and mapping of plots across the study area, site surveys and comparison of mapped data, and 3D-Modelling and Inter-Building Shading Analysis [9].

Nepal, with mean solar radiation of $4.7 \mathrm{kWh} / \mathrm{m}^{2}$ per day and a surface area of $1,47,181$ $\mathrm{km}^{2}$, is the region in South East Asia with a tremendous amount of solar energy potential [10]. The country is mainly divided into three different geographical regions namely Himalayan, Hilly and Terai regions. With a total width of $193 \mathrm{~km}$ from south to north, Nepal consists of altitude varying from 70 meters to 8848 meters [11]. Gorkha Bazzar is located in the central Hilly region of Nepal and is in state number 4. As being located at the central region of the nation in the Hilly region, which occupies most of the land area of Nepal, the Gorkha Bazzar is determined to be an ideal location for this research so that its outcome can generalize the circumstances of most of the Hilly region i.e. the maximum area of the nation. Also, as the Himalayan region has a lower potential for solar energy due to climatic circumstances and the Terai region is connected almost entirely to the national grid, it is Hilly region where connection to the grid is difficult due to topography and the potential for the production seems fair. Therefore, Gorkha is considered to be the proper place to carry out this work. At the time of the 2011 Nepal Census, it had a population of 49,272 people living in 13,127 individual households [12]. For this research, the population of ward no 6 of Gorkha Municipality is taken which has altogether 550 households.

Furthermore, the exponentially increasing construction in recent years and the deficit of conventional energy sources justify any initiatives conducive to the construction of self-sustainable buildings capable of producing their own energy for operating the electrical appliances. So the focus of this research is primarily towards estimating the solar energy potential from PV cells installed in the rooftops of the buildings of the 
ward. This research would be a stepping stone for the achievement of energy sustainability in the Municipality and can help to replicate the concept in other areas of the Hilly region.

\section{Methodology}

The major objective of this research is to estimate the energy capacity of photovoltaic solar energy systems that could be installed on the rooftops of the buildings in a ward of Gorkha Municipality of Gorkha district Nepal after implementation of Maximum Power Point Tracking Algorithm. So, to carry out this research, we went through the following steps. At first, the buildings were described in terms of construction data provided by the municipality. After getting the data, a sample survey was performed in the ward to get the information about the roof surface area where we can install the photovoltaic solar panel. A representative sample of buildings was chosen, and then, their roof surface area was statistically determined.

The geometric categorization of three building types (i.e. RCC rooftop type residential building, Fabric or metallic rooftop type residential building and Commercial or Institutional building) made it possible to obtain the useful roof surface where photovoltaic arrays could be installed. Then was the task of photovoltaic solar array design. After that, the energy potential was calculated for each of the buildings using the relationship below:

$$
\mathrm{E}=\mathrm{A} * \mathrm{r} * \mathrm{H} * \mathrm{PR}
$$

Where,

$\mathrm{E}=$ Solar Energy $(\mathrm{kWh})$

$\mathrm{A}=$ Total Area of Solar panel $(\mathrm{m} 2)$

$\mathrm{r}=$ solar panel yield or efficiency $(\%)$

$\mathrm{H}=$ Average solar radiation on tilted panels per year (shadings not included)

$\mathrm{PR}=$ Performance ratio, coefficient for losses (range between 0.5 and 0.9 , default value $=0.75)[13]$

Now, the implementation of the maximum power tracking algorithm was done to determine the final estimated value of electric potential.

\subsection{Categorization of Buildings and calculation of total Roof Surface Area}

At first, the data of building construction provided by the municipality was used to categorize the buildings in the entire ward. In the process, it was found that the total number of buildings in the ward is 550 among which, 225 are RCC rooftop buildings, 300 are triangular or metallic rooftop buildings and 25 of them were the commercial or institutional buildings having significantly larger roof surface area in comparison to 
residential buildings. After the determination of the number of buildings and their total roof surface area, the mean surface area for each type of buildings was calculated. Now, the number of buildings of each type was multiplied with the respective mean total surface area to obtain the total surface area of the different types of buildings.
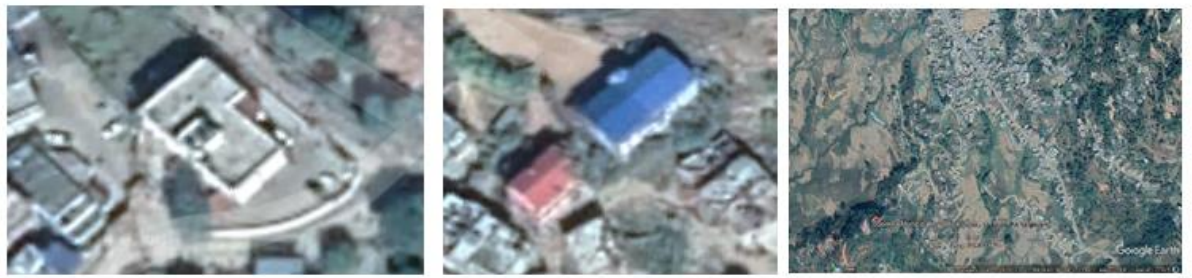

Fig. 1(a). Commercial or Institutional Rooftops Fig. 1(b). Fabric/metallic rooftop seen through Google Map Fig. 1(c). Rooftops of the buildings in Gorkha Municipality seen through Google Map

\subsection{Estimation of Roof Surface Area that can be used for Solar Panel Installation}

After the determination of the total surface area of each type of buildings, the useful surface area for them is calculated. For this estimation, we performed the sample survey with the building owners and determined the average area required by them for other purposes. The result of this survey is summarized in the table below.

Table 1. Building characterization and Useful Surface Area

\begin{tabular}{llll}
\hline $\begin{array}{l}\text { Type/Other } \\
\text { Characteristics }\end{array}$ & RCC Rooftops & $\begin{array}{l}\text { Fabric/Metallic } \\
\text { Rooftops }\end{array}$ & $\begin{array}{l}\text { Commercial } \\
\text { RCC rooftops }\end{array}$ \\
\hline Numbers & 225 & 300 & 25 \\
Floor Surface Area & $700-900$ sq. ft. & $500-700$ sq. ft. & $1700-2000$ sq. ft. \\
Useful Surface Area & $60 \%$ & $50 \%$ & $80 \%$ \\
\hline
\end{tabular}

\subsection{Solar Potential in the region}

The solar potential available in one region of the earth is different from another region. For calculations involved in this research, an irradiance of $1 \mathrm{~kW} / \mathrm{m}^{2} /$ hour and the panel efficiency of $14 \%$ is used. So, the power generated from the solar panel of $1 \mathrm{Sq} . \mathrm{m}$ area without considering performance ratio is obtained to be $140 \mathrm{~W}$ [14]. Thus, the power generated by the solar panels that are placed at rooftops of each of the buildings of all three types, considering each of the parameters, is tabulated below. 
Table 2. Total Electric Potential

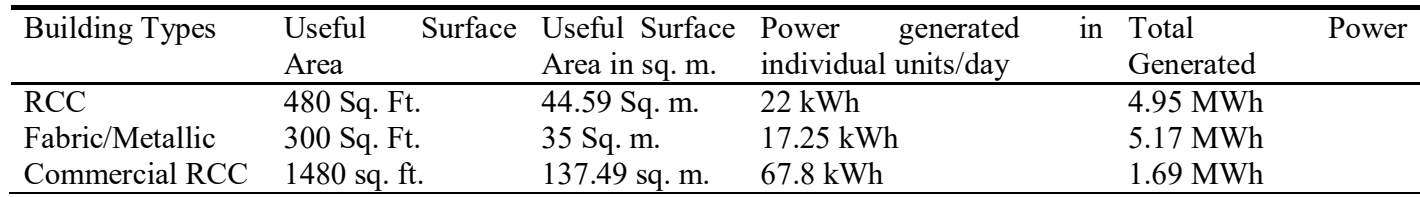

\subsection{Implementation of Online Data Logger}

The data logger helps to log the current and voltage output from the panel. It not only records the voltage and current but also indicates the 3-day peak power. This helps us to identify whether the output from the panel is less due to the absence of the sun or due to dust accumulation in the panel. For designing online data logger, an Arduino, a current sensor, a voltage sensor, ESP32 Wi-Fi module and Pre-Processor Hypertext (PHP) scripting language are used. The current and voltage sensor detects the amount of current and voltage received from the panel which is then thrown to the MYSQL database using Wi-Fi module every hour. Now this received data is analyzed to determine 3-day peak power. If this power is below a predefined threshold level, the end user is notified that the solar panel requires the maintenance.

\subsection{Implementation of MPPT and Solar Prioritizer}

Maximum power point tracking algorithm is used in order to enhance the output power from the PV system. There are numbers of such algorithms. In this research, we have implemented the Incremental conductance method to do so. The incremental conductance method is based on the fact that the slope of the PV array power curve is zero at the MPP, positive on the left of MPP and negative on the right. Similarly, the implementation of the MPPT along with Solar Prioritizer, which is microcontroller based automatic device for tracking the power supply from the panel and optimally controlling the output power from the system, the efficiency of the solar PV cell is found to be increased by $33 \%$ [15]. Now considering the use of MPPT and solar Prioritizer, the total amount of power that can be generated by placing the rooftops solar PV cells in Gorkha Bazzar is illustrated in the table below.

Table 3. Total Electric Potential after application of MPPT

\begin{tabular}{ccrr}
\hline Building Types & $\begin{array}{c}\text { Power in } \\
\text { individual } \\
\text { units/day }\end{array}$ & $\begin{array}{l}\text { Total Power } \\
\text { Generated }\end{array}$ & $\begin{array}{l}\text { Power Generated } \\
\text { after Using MPPT }\end{array}$ \\
\hline RCC & $22 \mathrm{kWh}$ & $4.95 \mathrm{MWh}$ & $6.58 \mathrm{MWh}$ \\
Fabric/Metallic & $17.25 \mathrm{kWh}$ & $5.17 \mathrm{MWh}$ & $6.87 \mathrm{MWh}$ \\
Commercial & $67.8 \mathrm{kWh}$ & $1.69 \mathrm{MWh}$ & $2.24 \mathrm{MWh}$ \\
RCC & & & \\
Total & $107.5 \mathrm{kWh}$ & $11.81 \mathrm{MWh}$ & $15.69 \mathrm{MWh}$
\end{tabular}


Hence, the total capacity of the rooftop of buildings of the ward number 4 of the Gorkha Municipality is 15.69 MWh per day i.e., 5538.57 MWh in a year, taking 12 days for the maintenance of the solar panel per year.

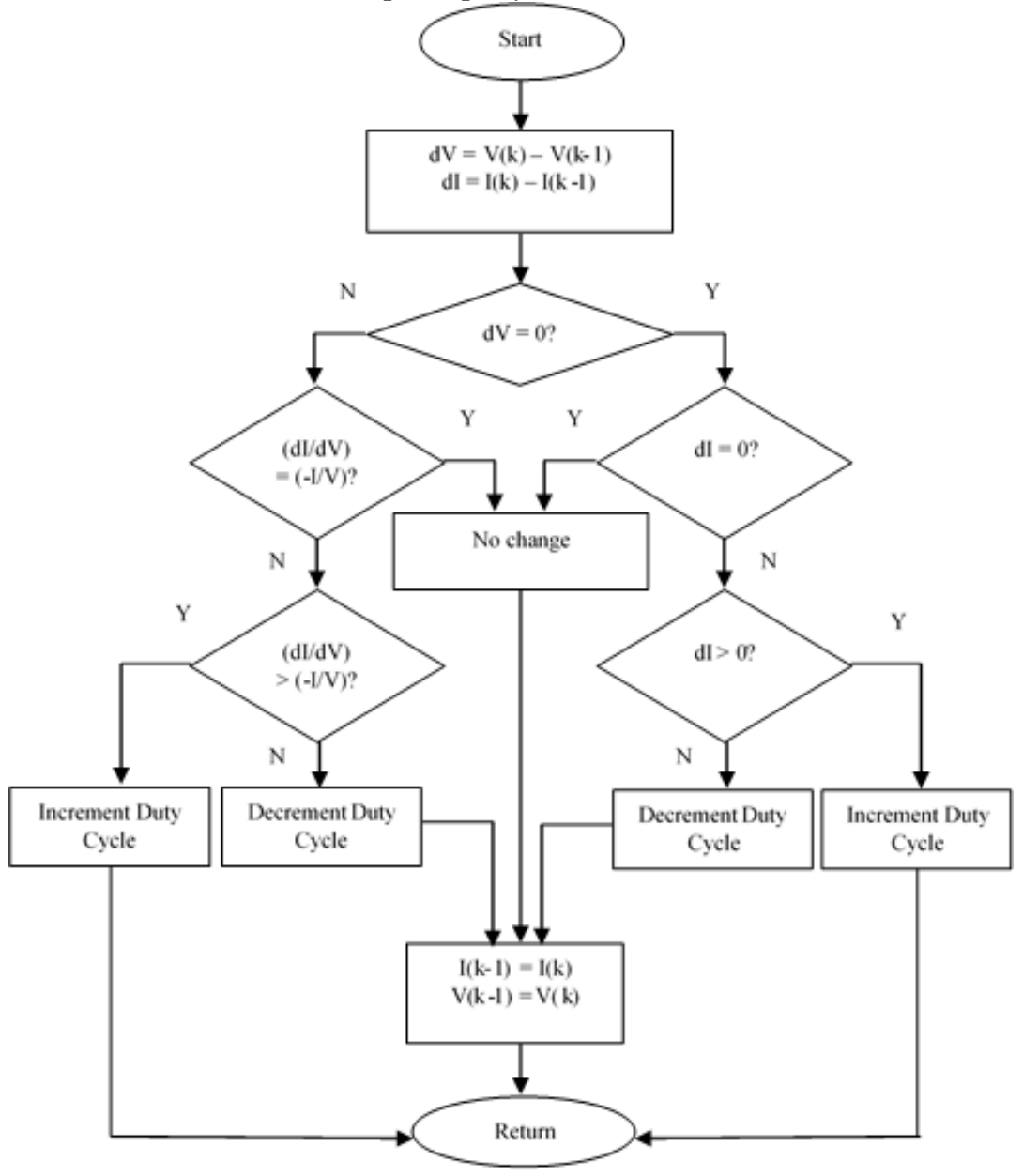

Fig. 2. Flowchart of Incremental Conductance Method

\section{Conclusions}

Nepal, being a country with most of the land covered with Hills and Mountains, is always a challenging region for expanding the Grid Connections throughout the nation. Also, the total Solar Potential seen in the nation makes Solar Energy always a reliable 
source of renewable energy. Due to this Solar PV cells are becoming more and more popular in the country, especially for the off-grid rural community.

Hence, after the implementation of the incremental conductance MPPT algorithm, the total estimated capacity per day of the ward is $15.69 \mathrm{MWh}$. And, the total estimated capacity per year of the ward is $5538.57 \mathrm{MWh}$. The capacity can be improved by incorporating Online Data logger in further advanced applications and designing according to Sun-Path Diagram. This research can be replicated to the household of whole Hilly region of Nepal and create energy sustainability in the nation.

Acknowledgments. This study acknowledges the local government of Gorkha Municipality, Gorkha District, Nepal for providing the necessary data for this research. Also, the authors would like to acknowledge the local people of ward number 6 of Gorkha Municipality, Nepal. Moreover, the Alternative Energy Promotion Center Nepal is also acknowledged for providing data of solar PV installation in Nepal. 


\section{References}

1. Dhakal , R., Bajracharya , T. R., Shakya , S. R., Kumal , B., Khanal , K., Williamson, S. J. \& Ghale, D. P. (2017, November ). Computational and experimental investigation of runner for gravitational water vortex power plant. In 2017 IEEE 6th International Conference on Renewable Energy Research and Applications (ICRERA) (pp. 365-373). IEEE.

2. Dhakal, R., Nepal, A., Acharya, A., Kumal, B., Aryal, T., Williamson, S. J \& Devkota, L. (2016, November). Technical and economic prospects for the site implementation of a gravitational water vortex power plant in Nepal. In 2016 IEEE International Conference on Renewable Energy Research and Applications (ICRERA) (pp. 1001-1006). IEEE.

3. T. Seitz, D. Pinner and P. Lorenz, "The economics of solar power," The McKinsey Quarterly - Energy, Resources, Materials - Strategy \& Analysis, 1 August 2008.

4. E. Baker, M. Fowlie, D. Lemoine and S. S. Reynolds, "The Economics of Solar Electricity," 2013.

5. M. Luqman, S. R. Ahmad, S. Khan, U. Ahmad, A. Raza and F. Akmal, "Estimation of Solar Energy Potential from Rooftop of Punjab Government Servants Cooperative Housing Society Lahore Using GIS," Smart Grid and Renewable Energy, vol. 6, pp. 128-139, 2015.

6. J. Ceballos, M. Pozo and E. Quirós, "Solar potential of rooftops in Cáceres city, Spain," Journal of Maps, vol. 14, no. 1, pp. 44-51, 2018.

7. N. R. Mandal and K. Saha, "Estimating Solar PV Potential for Sustainable Energy Planning in Tier-II Cities of India: Case of Bhopal City," Current Urban Studies, vol. 4, pp. 356-375, 2016.

8. R. Margolis, P. Gagnon, J. Melius, C. Phillips and R. Elmore, "Rooftop Solar Photovoltaic Technical Potential in the United States: A Detailed Assessment," National Renewable Energy Laboratory, Denver, 2016.

9. A. Magal, A. Pimpalkhare, A. Kottantharayil, J. Vasi, K. Ramamritham, P. Jadhav, S. Jois, V. Kotak and V. Kuthanazhi, "Estimating the rooftop potential of Greater Mumbai," Mumbai, 2016.

10. K. N. Poudyal, B. K. Bhattarai, B. Sapkota, B. Kjeldstad and P. Daponte, "Estimation of the daily global solar radiation; Nepal experience," Measurement, vol. 46, no. 6, pp. 1807-1817, 2013.

11. Nepal Geography, "Nepal Geography," Nepal Geography, 2019. [Online]. Available: https://www.worldatlas.com/webimage/countrys/asia/nepal/npland.htm\#page . [Accessed 27 January 2019]. 
12. "National Population and Housing Census 2011," Central Bureau of Statistics, Kathmandu, 2011.

13. A. S. Bahakeem, "A Hybrid Renewable Energy Model For Medina City of Saudi Arabia Using Integer Linear Programming," IOSR Journal of Electrical and Electronics Engineering (IOSR-JEEE), vol. 9, no. 5, pp. 7-11, 2014.

14. S. Ramaswamy and P. K. Sadhu, "Forecasting PV power from solar irradiance and temperature using neural networks," International Conference on Infocom Technologies and Unmanned Systems (Trends and Future Directions) (ICTUS), 2017.

15. S. Gautam, D. Raut, R. Dhakal, D. Ghale and P. Neupane, "Maximum Power Point Tracker with Solar Prioritizer in Photovoltaic Application," in 5th International Conference on Renewable Energy Research and Application, Birmingham, 2016. 